\title{
Characterisation of VanA and VanB elements from glycopeptide-resistant Enterococcus faecium from Greece
}

\author{
E. DEMERTZI†, M-F. I. PALEPOU, M. E. KAUFMANN*, A. AVLAMIS $\dagger$ and N. WOODFORD \\ Antibiotic Resistance Monitoring and Reference Laboratory and * Laboratory of Hospital Infection, Central \\ Public Health Laboratory, 61 Colindale Avenue, London NW9 5HT and †Microbiology Department, Laikon \\ General Hospital, Athens, Greece
}

\begin{abstract}
Ten glycopeptide-resistant Enterococcus faecium isolates from separate patients in Laikon General Hospital, Athens were studied. Eight isolates had the VanA phenotype and represented variants of three strains based on SmaI macrorestriction banding patterns. Their VanA elements were compared with the prototype element, Tn1546, by an overlapping PCR method. Three related isolates contained resistance elements indistinguishable from Tn1546 (designated Greek type I). The other five isolates all contained identical elements that differed from Tn1546 by the presence of IS1251 between vanS and vanH, by a point mutation $(\mathrm{G} \rightarrow \mathrm{T})$ at nucleotide position 8234 within $\operatorname{van} X$ and by a partial loss of transposition gene orf1 (designated Greek type II). Two distinct strains of $E$. faecium with the VanB phenotype were obtained. HhaI digestion of an amplified fragment of the $v a n B$ gene indicated that both strains contained the vanB2 allele, and further PCR assays confirmed that the vanB2 gene cluster was located within a Tn5382-like element.
\end{abstract}

\section{Introduction}

The spread of glycopeptide-resistant enterococci (GRE) has caused increasing therapeutic problems in the USA and some parts of Europe, including the UK [1]. Enterococci may have intrinsic or acquired resistance to glycopeptides. Intrinsic resistance is represented by the VanC phenotype of Enterococcus gallinarum and E. casseliflavus/E. flavescens, and is due to the presence of a modified terminal dipeptide (D-alanyl-D-serine, instead of D-alanyl-D-alanine) in the peptidoglycan precursors. To date, four phenotypes of acquired glycopeptide resistance have been reported. Enterococci with the VanA, VanB and VanD phenotypes have peptidoglycan precursors that terminate in the depsipeptide D-alanyl-D-lactate [1], whereas VanE strains have D-alanyl-D-serine [2]. The vast majority of clinical problems caused by GRE are associated with isolates of E. faecium with the VanA or VanB phenotypes.

Received 10 Oct. 2000; revised version received 1 Feb. 2001; accepted 5 Feb. 2001.

Corresponding author: Dr N. Woodford

(e-mail: nwoodford@phls.org.uk).
The prototype VanA element is the $10.8-\mathrm{kb}$ transposon Tn1546, which carries the vanRSHAXYZ genes and transposition genes orf1 and orf2 [3]. VanA elements among UK isolates have been divided into 24 distinct groups [4], and further elements have been described in isolates from other countries. Each of these diverse elements shares the vanRSHAX cluster [5] and is believed to have evolved from a Tn1546 progenitor [6]. Sequences of the resistance genes are remarkably conserved, with only a few point mutations identified [6,7]. Rather, VanA elements vary by the presence of deletions and insertion sequences (IS) in the non-essential genes (orf1, orf2, vanY and vanZ) and the intergenic regions [5-9]. Thus, pinpointing IS elements may be useful for monitoring the dissemination and evolution of particular VanA elements [10].

In contrast, the vanB gene clusters that are responsible for the VanB phenotype show greater sequence divergence. Three van $B$ alleles, designated $\operatorname{van} B 1$, vanB2 and vanB3, have been described [11-13]. The vanB2 gene cluster appears to be the most widespread form among E. faecium in both the USA [14] and Europe $[11,15]$. The vanB2 gene cluster has been associated with two closely related transposons, Tn5382 $[16,17]$ and $\operatorname{Tn} 1549$ [18]. 
This paper reports the characterisation of eight VanA and two VanB isolates of E. faecium and their glycopeptide resistance elements from Laikon General Hospital in Athens.

\section{Materials and methods}

\section{Isolates}

Between April 1998 and Sept. 1999, 10 isolates of E. faecium with VanA or VanB glycopeptide resistance were isolated at Laikon General Hospital in Athens. Eight VanA isolates included three from clinical samples of separate patients and five from rectal swabs of patients in the ICU and haematology units. Two VanB isolates were from clinical samples of patients in the ICU. These isolates were included in the present study for the molecular characterisation of their VanA and VanB elements. Strains used as controls were: $E$. faecium BM4147 containing Tn1546 [3]; E. faecium Tn\#3 with a VanA element assigned to group D (from a study that defined 24 distinct VanA elements present in GRE from the UK) [5]; E. faecalis ATCC 51299 with the vanB1 allele [15]; and E. faecium strains D002 and 2781 with vanB2 alleles [15]. No control strain with the vanB3 allele was available for inclusion in this study.

\section{Species identification and genotype determination}

Species identification and glycopeptide resistance genotypes were confirmed by the multiplex PCR methods described by Dutka-Malen et al. [19] and Woodford et al. [20], respectively. The identification assay was modified by the addition of the primers specific for $d d l_{\text {E.avium }}$ (E. avium-A 5'-GTT CCA GTC CTA AAA AAC C-3' and E. avium-B 5'-GCT TCT TCC TTT ACG ACC-3'), designed to amplify a 290-bp fragment corresponding to nucleotides 121-411 of GenBank U39774.

\section{Susceptibility testing}

The susceptibilities of isolates to vancomycin and teicoplanin were determined on Diagnostic Sensitivity Test (DST) Agar (Oxoid) supplemented with lysed horse blood $5 \%$. The inoculum was $10^{4}-10^{5} \mathrm{cfu} /$ spot. MICs were read after incubation for $18 \mathrm{~h}$ at $37^{\circ} \mathrm{C}$.

\section{DNA banding pattern polymorphism}

Pulsed-field gel electrophoresis (PFGE) of SmaIdigested genomic DNA was performed by a modification of a method described previously [21]. Electrophoresis was performed by the contour-clamped homogeneous electric field method with a CHEF-DRII drive module (BioRad, Hemel Hempstead, Hertfordshire) at $200 \mathrm{~V}$ for $30 \mathrm{~h}$, with a ramp rate of $1-35 \mathrm{~s}$ through agarose $1.2 \%$ at $12^{\circ} \mathrm{C}$. Banding patterns were analysed with GelCompar software (Applied Maths,
Kortrijk, Belgium). The patterns were interpreted initially in accordance with the general criteria proposed by Tenover et al. [22]; thus, isolates showing three or fewer band differences were regarded as closely related and those with four-to-six differences as possibly related. Patterns were also considered according to the specific recommendations of Morrison et al. for E. faecium, which emphasised the large degree of PFGE band polymorphism possible among epidemiologically related isolates considered to belong to the same strain when analysed by multiple methods [23].

\section{Characterisation of VanA resistance elements}

VanA resistance elements were initially characterised by PCR with 10 pairs of overlapping primers [3]. The elements were compared with Tn1546 for the presence, absence and relative sizes of amplicons obtained with each primer pair as described previously [4].

A 424-bp fragment of the vanX gene (nucleotides $8082-8505$ of $\operatorname{Tn} 1546$ ) was amplified by PCR and a $\mathrm{G} \rightarrow \mathrm{T}$ point mutation at position 8234 was sought by Dde I digestion of the amplicon as described previously [5].

Isolates were screened with primers designed to detect an IS $1216 \mathrm{~V} / \mathrm{IS} 3$ complex and the linkage of IS3 with orf1, both of which have been found in VanA elements with the mutation at position $8234[5,7]$. They were also screened with primers specific for IS1251 [7,9]. An IS1251 amplicon was labelled with digoxigenin (Roche, Lewes) and used in hybridisation studies with Southern blots prepared from selected PCR amplicons under stringent conditions at $68^{\circ} \mathrm{C}$. Hybrids were detected colorimetrically.

\section{Characterisation of VanB resistance elements}

A 589-bp fragment of the vanB gene [24] was amplified and digested with $H h a \mathrm{I}$ to identify the particular allele present [15]. Based on analysis of sequences in GenBank, amplicons of vanB1 alleles were predicted to give Hha I fragments of $323 \mathrm{bp}$ and $266 \mathrm{bp}$; those of vanB2 alleles, fragments of $429 \mathrm{bp}$ and $160 \mathrm{bp}$; those of vanB3 alleles, fragments of $357 \mathrm{bp}, 160 \mathrm{bp}$ and $72 \mathrm{bp}$. The amplification conditions were as described previously [24].

The association of vanB2 alleles with a Tn5382-like element was sought by using two pairs of primers $[16,25]$. A 311-bp fragment of the left end of Tn5382 was amplified with primers $5^{\prime}$-ACG CCA TGC TAT TTA CTT CCG GC-3' and 5'-GTT CTT ATT CCG CAG GTG GTG ATT-3'. A 1581-bp fragment containing $\operatorname{van} X_{B 2}$ and part of the right end of Tn5382 was amplified with primers 5'-TTG CAT GGT GTT CGT TGG-3' and 5'-CGG CAT CAA CGC CTT TAG-3'. 


\section{Results}

Species identification, genotyping and susceptibility testing

The 10 isolates of GRE included in this study were all confirmed as E. faecium in a multiplex PCR assay. The vanA gene was detected in eight isolates, with vanB detected in the two others. All isolates were resistant to vancomycin (MICs $>32 \mathrm{mg} / \mathrm{L}$ ). The glycopeptide resistance phenotype of each isolate was consistent with its genotype, i.e., vanA isolates were resistant to teicoplanin (MICs $>32 \mathrm{mg} / \mathrm{L}$ ), whereas vanB isolates were sensitive to teicoplanin (the MIC for one isolate was $2 \mathrm{mg} / \mathrm{L}$ and the MIC for the other was $4 \mathrm{mg} / \mathrm{L}$ ).

\section{Characterisation of GRE by PFGE}

The eight VanA isolates showed seven macrorestriction banding patterns (Fig. 1a). Isolates 1 and 2 were closely related, but isolate 8 also showed a similar banding pattern to these and was considered to be related, although a skewed gel prevented its satisfactory normalisation. The remaining five VanA isolates each had different banding patterns and were considered to be distinct by rigid interpretative criteria [22]. However, allowing for the banding polymorphism possible between isolates of E. faecium known to belong to a single strain [23], isolates 3 and 4 and isolates 5, 6 and 7 were considered to represent variants of two strains. The two VanB isolates (9 and 10) gave PFGE banding patterns that were distinct from each other (Fig. 1b) and from the patterns observed among the VanA strains.

\section{Characterisation of VanA resistance elements}

Overlapping fragments, amplified with 10 pairs of primers, indicated that isolates 1,2 and 8 contained VanA elements indistinguishable from Tn1546 (Table 1). Interestingly, these isolates appeared related by PFGE. These elements were designated Greek type I. The remaining five VanA isolates had elements that had only eight of the 10 amplicons in common with Tn1546. None of these isolates gave a product with primer pair $\mathrm{p} 1 \mathrm{p} 2$, which corresponds to nucleotides 22-1330 of Tn1546 (including part of orf 1 and of the left inverted repeat region), and all gave a larger amplicon than $\mathrm{Tn} 1546$ with primer pair $\mathrm{p} 11 \mathrm{p} 12$, which span nucleotides 4675 (in vanR) -6353 (in vanH) of Tn1546 (Table 1). The elements from these five isolates were designated Greek type II. a
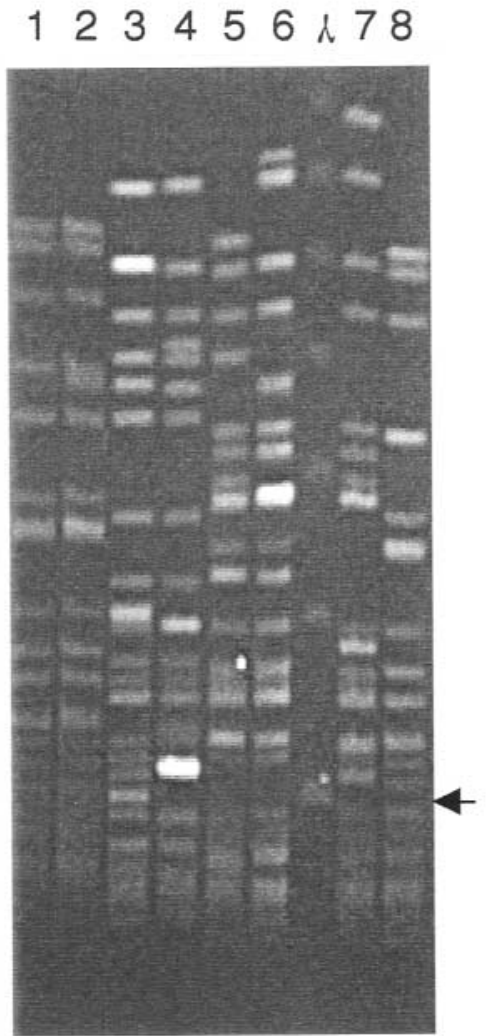

b

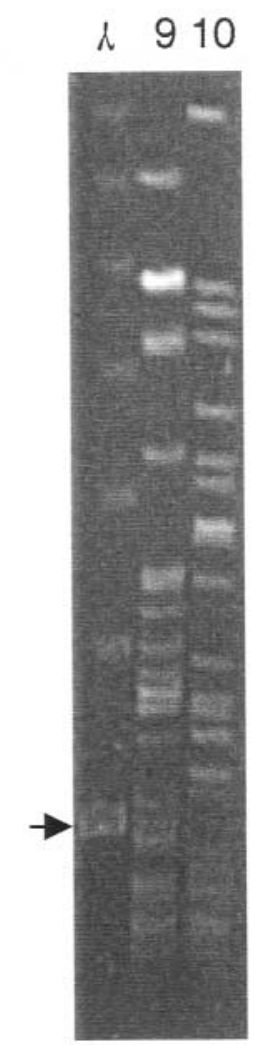

Fig. 1. PFGE of SmaI-digested DNA of (a) VanA and (b) VanB enterococci from Laikon General Hospital. The mol. wt marker is a concatamer of phage $\lambda$ DNA and the $48.5-\mathrm{kb}$ band is marked with an arrow. 
Dde I digestion of a 424-bp internal fragment of the vanX gene that had been amplified from the three isolates with type I VanA elements yielded three fragments of $185 \mathrm{bp}, 149 \mathrm{bp}$ and $90 \mathrm{bp}$, which were indistinguishable in size from those obtained from a Tn1546 control. However, vanX amplicons from the five isolates with type II VanA elements yielded only two Dde I fragments of $239 \mathrm{bp}$ and $185 \mathrm{bp}$, as observed in control Tn\#3 with a group D element. These two fragments were consistent with the presence of the $\mathrm{G} \rightarrow \mathrm{T}$ point mutation at position 8234 (Table 1) [5]. We have shown previously that VanA elements belonging to group D lack a p1p2 amplicon and have the mutation at position 8234 . In group D elements the first 120 bases of $\operatorname{Tn} 1546$ are replaced by an IS1216V/ IS3 complex linked to the remaining part of orf1 (Table 1) [5]. Therefore, the Greek type II elements were compared further with a group D control. However, these elements did not yield amplicons with primers specific for the IS1216V/IS3 complex or IS3orfl linkage (Table 1).

The large p11p12 amplicon observed in Greek type II VanA elements suggested a possible insertion in the vanS-vanH intergenic region. IS 1251 has been reported at this position in some VanA elements from the USA [9]. A 427-bp IS1251-specific fragment was amplified from all five isolates harbouring type II VanA elements. Furthermore, an IS1251-specific probe hybridised with Southern blots prepared from the $\mathrm{p} 11 \mathrm{p} 12$ amplicons of the five type II elements, confirming the presence of this IS element on this fragment of the VanA elements. The IS1251 probe did not hybridise with the p11p12 amplicons of Tn1546 or Greek type I elements (Table 1).

\section{Characterisation of VanB resistance elements}

Amplification with $v a n B$-specific primers yielded a 589-bp fragment from two isolates. Restriction fragment-length polymorphism (RFLP) analysis with Hha I indicated that the amplicons from both isolates were derived from vanB2 alleles (Fig. 2). Both of the VanB isolates also gave products of $311 \mathrm{bp}$ and $1581 \mathrm{bp}$ when amplified with primers specific for the left and right ends of Tn5382, which confirmed that their vanB2 gene clusters were contained within a Tn5382-like element.

\section{Discussion}

We believe that this report represents the first characterisation of elements responsible for acquired glycopeptide resistance in enterococci from Greece. Eight isolates expressing the VanA phenotype had seven different macrorestriction banding patterns, as interpreted by published general criteria [22], but when the patterns were interpreted according to guidelines specifically designed for E. faecium [23], the isolates 


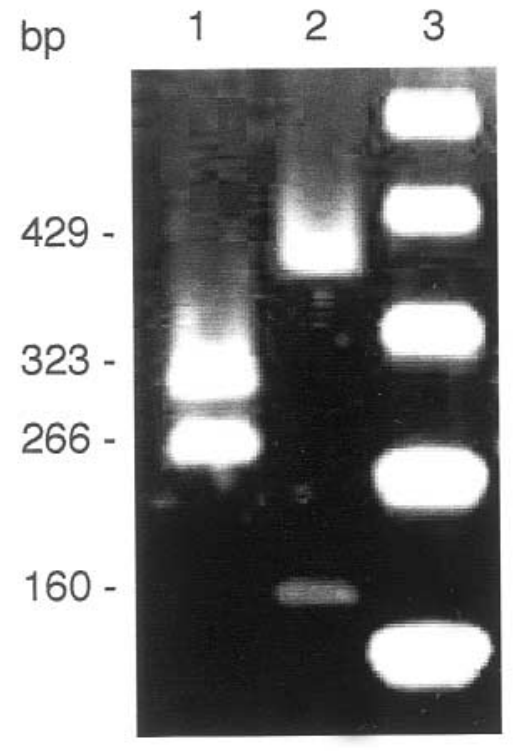

Fig. 2. Representative results for PCR-RFLP analysis of vanB amplicons with $H$ ha $\mathrm{I}$. Lane 1, vanBl allele; 2, vanB2 allele; 3, 123-bp ladder (Life Technologies, Paisley).

were considered to represent variants of only three strains. Two VanB isolates were also studied; their macrorestriction banding patterns were distinct from each other and from those of the VanA strains.

Despite diversity among the resistant strains, the VanA resistance elements were divided into only two types. Elements designated Greek type I were identified in three related isolates and were indistinguishable from Tn1546 [3] and group A elements from the UK [4]. Greek type II elements were identified in five isolates that represented variants of two strains. These elements contained IS1251 in the vanS-vanH intergenic region, had a mutation within vanX and a deletion in orf1. Type II elements were distinct from all of the 24 groups of VanA elements identified among GRE from the UK [4]; they shared the mutation in vanX and absence of a p1p2 amplicon with group D elements, but differed by the presence of IS1251 and by the absence of an IS1216V/IS3-orf1 complex at the $5^{\prime}$ end of the element [5]. They resemble elements designated types F1 and F2 that were characterised from enterococci from the USA [6]. Indeed, VanA elements containing IS 1251 were originally identified in GRE from the USA, where they are locally prevalent [9]. Such elements have recently been identified in one GRE from Norway and in two from the Republic of Ireland [26], but apparently remain rare in Europe as a whole $[4,6,7]$. The reason for the appearance of VanA elements containing IS1251 in Laikon General Hospital is unclear. There were no discernible epidemiological links with countries from which these elements have been reported previously.

Two distinct strains of E. faecium with VanB gly- copeptide resistance were obtained. Both contained the vanB2 allele as part of a gene cluster within a $\operatorname{Tn} 5382-$ like element. These findings are consistent with other studies of the genetic basis of VanB resistance in enterococci from Europe $[11,15,25]$. Horizontal transmission of vanB2 as part of Tn5382 has also been documented in diverse strains from across the USA [14].

We are grateful to Karen McGregor (University of Dundee) for supplying E. faecalis ATCC 51299 and E. faecium D-002. E.D. thanks the National Research Institute of Greece and the Greek Society of Microbiology for the funding to undertake this work.

\section{References}

1. Woodford N. Glycopeptide-resistant enterococci: a decade of experience. J Med Microbiol 1998; 47: 849-862.

2. Fines M, Perichon B, Reynolds P, Sahm DF, Courvalin P. VanE, a new type of acquired glycopeptide resistance in Enterococcus faecalis BM4405. Antimicrob Agents Chemother 1999; 43: 2161-2164.

3. Arthur M, Molinas C, Depardieu F, Courvalin P. Characterization of Tn1546, a Tn3-related transposon conferring glycopeptide resistance by synthesis of depsipeptide peptidoglycan precursors in Enterococcus faecium BM4147. J Bacteriol 1993; 175: 117-127.

4. Woodford N, Adebiyi A-MA, Palepou M-FI, Cookson BD. Diversity of VanA glycopeptide resistance elements in enterococci from human and nonhuman sources. Antimicrob Agents Chemother 1998; 42: 502-508.

5. Palepou M-FI, Adebiyi A-MA, Tremlett CH, Jensen LB, Woodford N. Molecular analysis of diverse elements mediating VanA glycopeptide resistance in enterococci. $J$ Antimicrob Chemother 1998; 42: 605-612.

6. Willems RJL, Top J, van den Braak $\mathrm{N}$ et al. Molecular diversity and evolutionary relationships of Tn1546-like elements in enterococci from humans and animals. Antimicrob Agents Chemother 1999; 43: 483-491.

7. Jensen LB, Ahrens P, Dons L, Jones RN, Hammerum AM, Aarestrup FM. Molecular analysis of Tn1546 in Enterococcus faecium isolated from animals and humans. J Clin Microbiol 1998; 36: 437-442.

8. MacKinnon MG, Drebot MA, Tyrell GJ. Identification and characterization of IS1476, an insertion sequence-like element that disrupts VanY function in a vancomycin-resistant Enterococcus faecium strain. Antimicrob Agents Chemother 1997; 41: $1805-1807$.

9. Handwerger S, Skoble J, Discotto LF, Pucci MJ. Heterogeneity of the vanA gene cluster in clinical isolates of enterococci from the Northeastern United States. Antimicrob Agents Chemother 1995; 39: 362-368.

10. da Costa Darini AL, Palepou M-FI, Woodford N. Nucleotide sequence of IS1542, an insertion sequence identified within VanA glycopeptide resistance elements of enterococci. FEMS Microbiol Lett 1999; 173: 341-346.

11. Dahl KH, Simonsen GS, Olsvik O, Sundsfjord A. Heterogeneity in the $v a n B$ gene cluster of genomically diverse clincal strains of vancomycin-resistant enterococci. Antimicrob Agents Chemother 1999; 43: 1105-1110.

12. Gold HS, Ünal S, Cercenado $\mathrm{E}$ et al. A gene conferring resistance to vancomycin but not teicoplanin in isolates of Enterococcus faecalis and Enterococcus faecium demonstrates homology with vanB, vanA, and vanC genes of enterococci. Antimicrob Agents Chemother 1993; 37: 1604-1609.

13. Patel R, Uhl JR, Kohner $\mathrm{P}$ et al. DNA sequence variation within vanA, vanB, vanC-1 and vanC2/3 genes of clinical Enterococcus isolates. Antimicrob Agents Chemother 1998; 42: 202-205.

14. Hanrahan J, Hoyan C, Rice LB. Geographic distribution of a large mobile element that transfers ampicillin and vancomycin resistance between Enterococcus faecium strains. Antimicrob Agents Chemother 2000; 44: 1349-1351.

15. McGregor KF, Young H-K. Identification and characterization of vanB2 glycopeptide resistance elements in enterococci 
isolated in Scotland. Antimicrob Agents Chemother 2000; 44: 2341-2348.

16. Carias LL, Rudin SD, Donskey CJ, Rice LB. Genetic linkage and cotransfer of a novel, vanB-containing transposon (Tn5382) and a low-affinity penicillin-binding protein 5 gene in a clinical vancomycin-resistant Enterococcus faecium isolate. J Bacteriol 1998; 180: 4426-4434.

17. Dahl KH, Lundblad EW, Røkenes TP, Olsvik Ø, Sundsfjord A. Genetic linkage of the vanB2 gene cluster to Tn5382 in vancomycin-resistant enterococci and characterization of two novel insertion sequences. Microbiology 2000; 146: 14691479.

18. Garnier F, Taourit S, Glaser P, Courvalin P, Gallimand M. Characterization of transposon Tn1549, conferring VanB-type resistance in Enterococcus spp. Microbiology 2000; 146: 1481-1489.

19. Dutka-Malen S, Evers S, Courvalin P. Detection of glycopeptide resistance genotypes and identification to the species level of clinically relevant enterococci by PCR. J Clin Microbiol 1995; 33: 24-27 (erratum J Clin Microbiol 1995; 33: 1434).

20. Woodford N, Morrison D, Johnson AP et al. Plasmid-mediated vanB glycopeptide resistance in enterococci. Microb Drug Resist 1995; 1: 235-240.

21. Murray BE, Singh KV, Markowitz SM et al. Evidence for clonal spread of a single strain of $\beta$-lactamase-producing Enterococcus (Streptococcus) faecalis to six hospitals in five states. J Infect Dis 1991; 163: 780-785.

22. Tenover FC, Arbeit RD, Goering RV et al. Interpreting chromosomal DNA restriction patterns produced by pulsedfield gel electrophoresis: criteria for bacterial strain typing. J Clin Microbiol 1995; 33: 2233-2239.

23. Morrison D, Woodford N, Barrett SP, Sisson P, Cookson BD. DNA banding pattern polymorphism in vancomycin-resistant Enterococcus faecium and criteria for defining strains. J Clin Microbiol 1999; 37: 1084-1091.

24. Woodford N, Jones BL, Baccus Z, Ludlam HA, Brown DFJ. Linkage of vancomycin and high-level gentamicin resistance genes on the same plasmid in a clinical isolate of Enterococcus faecalis. J Antimicrob Chemother 1995; 35: 179-184.

25. McGregor KF, Nolan C, Young H-K, Palepou M-FI, Tysall L, Woodford N. Prevalence of the vanB2 gene cluster in VanB glycopeptide-resistant enterococci in the United Kingdom and the Republic of Ireland and its association with a Tn5382-like element. Antimicrob Agents Chemother 2001; 45: 367-368.

26. Simonsen GS, Myhre MR, Dahl KH, Olsvik O, Sundsfjord A. Typeability of Tn1546-like elements in vancomycin-resistant enterococci using long-range PCRs and specific analysis of polymorphic regions. Microb Drug Resist 2000; 6: 49-57. 